\title{
GAMBARAN BURNOUT PADA PERAWAT KESEHATAN JIWA
}

\author{
Triyana Harlia Putri \\ Fakultas Kedokteran Program Studi Keperawtan, \\ Universitas Tanjungpura, Kota Pontianak, Indonesia \\ *triyana.harliaputri@ners.untan.ac.id
}

\begin{abstract}
Mental health nurses face challenges in caring for mental patients. These challenges can cause stress during work and drain nurses emotionally and physically or burnout. This study aims to determine the description of burnout in mental health nurses. The design of this research is analytic descriptive with cross sectional approach. The study was conducted at Jakarta Soeharto Heerdjan Hospital with a sample of 130 mental health nurses in total sampling. The instrument used was the Maslach Burnout Inventory-Human Service Survey. Data analysis uses frequency distribution and percentage. The results obtained from almost all nurses $113(86.9 \%)$ revealed a moderate level burnout. When viewed from each of the three burnout domains, almost all nurses $100(76.9 \%)$ felt emotional exhaustion, most 92 nurses (70.8\%) felt depersonalization and most nurses 98 (75.4\%) felt a personal accomplishment."Burnout felt by mental health nurses is at a moderate level and for all burnout domains that is emotional exhaustion, depersonalization, and personal accomplishment.". High levels are especially felt more by mental health nurses on the emotional exhaustion dimension.
\end{abstract}

Keyword: Burnout, Work Stress, Mental Health Nurses

\begin{abstract}
ABSTRAK
Perawat kesehatan jiwa menghadapi tantangan dalam merawat klien gangguan jiwa. Tantangan tersebut dapat menyebabkan stres selama bekerja dan menguras perawat secara emosional dan fisik atau burnout. Penelitian ini bertujuan untuk mengetahui gambaran burnout pada perawat kesehatan jiwa. Desain penelitian ini deskriptif analitik dengan pendekatan cross sectional. Penelitian dilakukan di RSJ Soeharto Heerdjan Jakarta dengan jumlah sampel 130 perawat kesehatan jiwa secara total sampling. Instrumen digunakan adalah Maslach Burnout Inventory- Human Service Survey. Analisis data menggunakan distribusi frekuensi dan persentase. Hasil penelitian didapatkan hampir dari seluruh perawat 113 (86,9\%) mengungkapkan burnout level sedang. Jika dilihat dari masing- masing ketiga domain burnout, hampir seluruh perawat 100 (76,9\%) merasakan kelelahan emosional, sebagian besar perawat 92 (70,8\%) merasakan depersonalisasi dan sebagian besar perawat 98 (75,4\%) merasakan penurunan pencapaian pribadi. Burnout yang dirasakan perawat kesehatan jiwa berada pada level sedang dan untuk semuan domain burnout yaitu kelelahan emosional, depersonalisasi, dan prestasi pribadi. Level tinggi terutama lebih banyak dirasakan oleh perawat kesehatan jiwa pada dimensi kelelahan emosional.
\end{abstract}

Kata kunci: Burnout, Stres Kerja, Perawat Kesehatan Jiwa 


\section{PENDAHULUAN}

Keperawatan jiwa merupakan area yang paling menarik dan menantang dalam praktik keperawatan. Fenomenafenomena yang terjadi pada perawat jiwa diketahui bahwa perawat mengalami stres yang berkepanjangan, apabila tidak segera diatasi akan berujung pada burnout. Menurut Teater \& Ludgate (2014) perawat kesehatan jiwa dan occupational therapist menempati angka tertinggi yaitu 54\% mengalami burnout dibandingkan psychologist, pediatric oncologist, medical doctors in general, working adult in general, medicine internal/resident dan child care worker. Menurut Fazelzadeh et al (2008) juga membandingkan burnout yang terjadi pada perawat rumah sakit, hasil studi mengindikasikan bahwa perawat-perawat di bangsal jiwa menunjukkan level yang lebih tinggi dibandingkan bekerja di bangsal internal, bedah, dan luka bakar. Perawat kesehatan jiwa merupakan profesi yang rentan mengalami burnout.

Burnout menjadi permasalahan global. Menurut Khamisa et al (2015) dalam studinya telah membandingkan tiga dimensi burnout di antara perawatperawat dari 8 negara berbeda yaitu AS, Kanada, Inggris, Jerman, Selandia Baru, Jepang, Rusia, dan Armenia) dan perawat-perawat Afrika Selatan mengalami burnout lebih tinggi ketimbang perawat yang bekerja di negara-negara lain. Penelitian yang dilakukan oleh Sermeus et al dan Galindo et al di Eropa tahun 2011 yaitu 30\% perawat melaporkan mengalami kelelahan dalam bekerja, $42 \%$ perawat Inggris mengalami penderitaan akibat burnout dan $44 \%$ perawat Yunani melaporkan ketidaknyamanan dalam bekerja (Ribeiro et al, 2014). Dari data di atas burnout dapat terjadi pada perawat dimana saja.

Burnout dapat dilihat dari ketiga dimensi atau yang disebut sindrom burnout. Menurut Ndetei et al (2008) perawat kesehatan jiwa di Kenya menunjukkan level burnout tinggi yaitu untuk poin kelelahan emosi $38 \%$ menunjukkan level tinggi, poin depersonalisasi 47,8\% menunjukan level tinggi pada dimensi burnout yang ini dan poin pencapaian personal $38,6 \%$ menunjukan level rendah. Penelitian lainnya, burnout pada perawat kesehatan jiwa di RSJ Prof. Dr. Muhammad Ildrem Medan, menunjukan burnout dengan kategori sedang (Damanik et al, 2015). Dari data diatas, burnout yang di alami perawat kesehatan jiwa dalam kategori sedang hingga tinggi.

Burnout mempunyai dampak pada perawat itu sendiri. Menurut Fradelos et al (2014) dampak tersebut terhadap kualitas hidup perawat. Menurut Bloom \& Farragher (2011) orang Jepang bahkan memiliki istilah, karoshi untuk kematian tiba-tiba yang dihasilkan dari pekerjaan yang berlebihan. Bahkan sampai terjadinya resiko bunuh diri atu tindakan bunuh diri (Warner, 2014). Beberapa gejala burnout seperti kelelahan fisik, emosional, depresi, frustasi, kebosanan, gangguan tidur, gangguan pencernaan dan sakit kepala (Maslach, 2003 dalam Holland et al, 2015). Sehingga, burnout dapat mengancam kesehatan dan kehidupan perawat.

Dampak dari burnout yang dirasakan tindak hanya pada kehidupan perawat. Dampak burnout sangatlah serius untuk klien dan institusi (Harkin \& Melby, 2014). Menurut Maslach \& Jackson (1981) dalam Warner (2014) mengatakan burnout juga berdampak pada kemerosotan quality of care. Hal ini muncul sebagai suatu faktor dalam turnover pekerjaan, ketidakpuasan pekerjaan, sampai niat meninggalkan pekerjaan. Menurut hasil survey American Helath Care Association (2011) tercatat tingkatan turnover perawat sebesar 39,5\%. Di Jakarta, tingkat 
turnover cukup tinggi di rumah sakit yaitu $27,3 \%$ pertahunnya. Sementara untuk tingkat ketidakpuasan kerja perawat menurut Survey Work Asia tahun 20072008 terhadap 11 negara Asia Fasifik, termasuk indonesia $51 \%$ karyawan melakukan pindah kerja (Alfiyah, 2013). Hal ini semakin menjelaskan banyak dampak yang disebabkan oleh burnout.
Banyak
faktor
yang

mempengaruhi terjadinya burnout. Faktor penyebab burnout menurut Maslach \& Jackson (1981) yaitu faktor-faktor lingkungan kerja (work overload, lack of control, insufficient reward, lack of community, unfairness, significant value conflict: moral distress), faktor-faktor personality, demografi (usia, gender, status pernikahan, status pendidikan, masa kerja). Sementara menurut Lee \& Ashforth (1996) yaitu tekanan pekerjaan (ambiguitas, konflik peran, stres kerja dan beban kerja). Sehingga, faktor penyebab burnout berasal dari faktor internal dan faktor eksternal dan saling berkaitan satu sama lain.

Berdasarkan studi pendahuluan yang telah dilakukan pada tanggal 15-16 Maret 2016 menggunakan kuesioner Maslach Burnout Inventory-Human Service Survey pada 10 orang perawat, hasil menunjukan total level burnout sedang, untuk poin kelelahan emosi $80 \%$ menunjukkan level tinggi dan 20\% menunjukkan level yang sedang. Untuk poin depersonalisasi $10 \%$ menunjukkan level tinggi, $80 \%$ menunjukkan level yang sedang dan $10 \%$ menunjukkan level rendah. Pencapaian personal dilaporkan oleh $10 \%$ menunjukkan level tinggi, $80 \%$ menunjukkan level sedang, $10 \%$ menunjukkan level rendah. Dari hasil wawancara terhadap salah satu anggota keluarga klien, didapatkan hasil bahwa ada beberapa perawat yang kurang tanggap, bersikap sinis, dan acuh saat di ajak bicara dan di tanya mengenai kondisi keluarga yang di rawat.
Di bawah kondisi seperti itu, akan berdampak kepada institusi, perawat dan klien akan cenderung menunjukkan kemajuan yang rendah, asuhan keperawatan jiwa dan kualitas pelayanan kesehatan jiwa akan berpengaruh. Berdasarkan fenomena diatas, maka peneliti tertarik ingin melakukan penelitianyang berjudul "Gambaran Burnout pada perawat kesehatan jiwa"

\section{METODE}

Jenis penelitian ini adalah penelitian deskriptif analitik kuantitatif dengan rancangan penelitian cross sectional. Populasi dalam penelitian ini adalah seluruh perawat kesehatan jiwa yang bekerja di rawat inap maupun IGD di RSJ Soeharto Heerdjan Jakarta berjumlah 130 orang dan teknik pengambilan sampel secara total sampling.

Analisis data dilakukan dengan analisis univariat dengan memaparkan domain burnout pada perawat kesehatan jiwa. Pengambilan data ini dilakukan dengan menggunakan lembar kuesioner yang terdiri MBI-Human Services Survey (MBI-HSS) mengukur tiga subskala burnout, "emotional exhaustion" "depersonalization" and "personal accomplishment."

\section{HASIL}

Hasil penelitian dijelaskan dan disajikan dalam bentuk tabel distribusi frekuensi.

Tabel Distribusi frekuensi burnout pada perawat kesehatan jiwa

\begin{tabular}{llll}
\hline Domain & Kategori & $\mathbf{F}$ & $\mathbf{\%}$ \\
\hline \multirow{2}{*}{$\begin{array}{l}\text { Kelelahan } \\
\text { Emosional }\end{array}$} & Tinggi & 17 & 13,1 \\
\cline { 2 - 4 } & Sedang & 100 & 76,9 \\
\cline { 2 - 4 } & Rendah & 13 & 10 \\
\hline \multirow{3}{*}{ Depersonalisasi } & Tinggi & 17 & 13,1 \\
\cline { 2 - 4 } & Sedang & 92 & 70,8 \\
\cline { 2 - 4 } & Rendah & 21 & 16,2 \\
\hline \multirow{2}{*}{$\begin{array}{l}\text { Pencapaian } \\
\text { Prestasi Pribadi }\end{array}$} & Tinggi & 18 & 13,8 \\
\cline { 2 - 4 } & Sedang & 98 & 75,4 \\
\cline { 2 - 4 } & Rendah & 14 & 10,8 \\
\hline \multirow{3}{*}{ Burnout } & Tinggi & 13 & 10 \\
\cline { 2 - 4 } & Sedang & 113 & 86,9 \\
\cline { 2 - 4 } & Rendah & 4 & 3,1 \\
\hline
\end{tabular}


Berdasarkan tabel, jika ditinjau burnout secara keseluruhan, hampir dari seluruh perawat $113(86,9 \%)$ mengungkapkan burnout level sedang. Jika dilihat dari masing- masing ketiga domain burnout, hampir seluruh perawat $100 \quad(76,9 \%)$ merasakan kelelahan emosional, sebagian besar perawat $92(70,8 \%)$ merasakan depersonalisasi dan sebagian besar perawat $98 \quad(75,4 \%)$ merasakan penurunan pencapaian pribadi.

\section{PEMBAHASAN}

Hasil penelitian menunjukkan bahwa, perawat kesehatan jiwa yang bekerja di rawat inap dan IGD Rumah Sakit Jiwa Dr. Soeharto Heerdjan, sebagian besar perawat mengalami burnout level sedang. Hasil ini agak sedikit berbeda oleh penelitian WilczekRuzyczka \& Kalicinska (2015) perawat kesehatan jiwa di Polandia Selatan menunjukkan level burnout rendah hingga sedang yaitu untuk poin kelelahan emosi menunjukkan level sedang, untuk poin depersonalisasi menunjukkan level sedang dan Level rendah dari pencapaian personal perawat. Penelitian lainnya dilakukan oleh Hamaideh (2011) hasil yang didapatkan burnout pada perawat di Jordania berada pada level tinggi. Penelitian yang dilakukan oleh Pogyoshan et al (2010) dimana membandingkan burnout yang terjadi di enam Negara yang berbeda yaitu U.S., Kanada, U.K, Jerman, New Zealand, dan Jepang. Hasil penelitian yang didapatkan hasil burnout level tinggi terjadi di Jepang. Nilai skor tertinggi pada kelelahan emosional dan depersonalisasi, sementara rendah pada penurunan pencaian prestasi. Kemudian, diikuti burnout pada level sedang di United Kingdom, New Zealand, dan Kanada, dan level rendah di Jerman. Burnout tersebut terjadi dikarenakan kontak interpersonal yang dekat dengan klien dan lingkungan praktik yang kompleks dapat menjadi predisposisi perawat mengalami burnout dan berimplikasi job performance mereka serta quality of care. Hal ini mungkin saja disebabkan oleh perbedaan kultural, economic, dan social differences dari berbagai Negara dimana memiliki variasi system kesehatan masing-masing.

Jika dilihat dari masing-masing domain burnout, perawat merasakan level tinggi untuk semua dimensi burnout terutama pada kelelahan emosional. Menurut asumsi peneliti, hal ini disebabkan oleh tingginya frekuensi burnout yang dirasakan perawat pada domain tersebut dan hampir seluruh perawat mengalami kelelahan emosional. Hal ini didukung oleh penelitian Lu (2008) kecendrungan tinggi untuk semua dimensi burnout terutama pada kelelahan emosional. Menurut Maslach \& Jackson (1981) dalam Holland (2015) menyatakan bahwa aspek kunci dari sindrom burnout adalah unsur pertama yaitu kelelahan emosional.

Sindrom burnout yaitu kelelahan emosional, depersonalisasi, dan prestasi pribadi akan saling mempengaruhi level burnout yang dirasakan perawat. Menurut Kusano et al (2013) level burnout tinggi apabila mencakup dimensi yaitu kelelahan emosi tinggi, depersonalisasi tinggi, dan pencapaian pribadi rendah. Level burnout sedang apabila kelelahan emosi dalam level sedang, depersonalisasi level sedang, dan prestasi pribadi level sedang. Level burnout rendah, kelelahan emosi rendah, depersonalisasi rendah, dan prestasi pribadi tinggi.

Tingginya level burnout juga didukung kurangnya dukungan sosial baik dari rekan kerja, tim medis lainnya maupun keluarga juga menjadi faktor pendukung terjadinya burnout. Selain itu, tidak berjalannya supervisi juga menyebabkan tingginya level burnout. 
Menurut Hamaideh (2011) menjelaskan rendahnya lingkungan kerja psikososial sebagai bukti yang dapat mempengaruhi burnout dan kurangnya social support dari teman atau rekan serta supervisors

Asumsi peneliti, dimana usia sangat erat kaitannya dengan pengalaman dalam bekerja dan merupakan salah satu faktor yang mempengaruhi burnout. Perawat muda ataupun perawat senior akan tetap mempengaruhi terjadinya burnout. Menurut Jaworek (2015) perawat senior mempunyai banyak pengalaman dan mempunyai prestasi pribadi yang baik meskipun demikian, level tinggi burnout juga dialami oleh perawat senior. Perawat yang berada di usia tidak lagi muda akan sulit memainkan peran sebagai perawat kesehatan jiwa dari pada memanajemen perasaannya. Selain itu, seiring bertambahnya usia, akan semakin tinggi stressor yang dimiliki.

Perawat muda juga merasakan burnout di situasi yang berbeda. Perawat muda mungkin lebih sensitif dan kesulitan dalam memberikan caring kepada klien sehingga burnout mungkin saja dirasakan. Menurut Geri \& Flynn (2008) burnout level tinggi pada perawat muda dikarena kurangnya pengalaman emosional yang penting selama menghadapi klien. Sehingga, perawat yang berada pada usia muda maupun tua tidak akan mempengaruhi terjadinya burnout.

Menurut asumsi peneliti, kecendrungan burnout juga dapat dialami oleh siapa saja yang bekerja dibidang human service, sehingga laki-laki maupun pria memiliki potensi yang sama mengalami burnout dengan reaksi yang berbeda-beda. Tidak dapat dihindari bahwa kepribadian dari individu juga berkontribusi terhadap burnout, laki-laki ataupun perempuan, individu tetap saja memiliki kepribadian yang berbeda. Menurut Lori (2015) karakter pribadi dengan sifat berhati-hati, perfectionis kecendrungan mengalami burnout begitu juga dengan kepribadian tipe $\mathrm{D}$, dimana kecendrungan memiliki emosi-emosi negatif dan hambatan sosial. Sehingga, baik laki-laki maupun perempuan tidak akan mempengaruhi terjadinya burnout.

Menurut asumsi peneliti, individu dengan tingkat pendidikan tinggi akan mengalami burnout karena memiliki kecendrungan tingkat stres yang tinggi yang disebabkan oleh tekanan dan tuntutan perawat sebagai role model. Sementara tingkat pendidikan rendah juga mengalami burnout karena rendahnya pendidikan individu tidak dapat berfikir luas, kurang berinisiatif dan kreatif, kurang memiliki banyak ide sehingga cenderung mengalami burnout.

Individu juga sukses dengan karirnya akan lebih sensitif dengan burnout. Menurut Maslach et al (2001) hal tersebut terjadi karena individu dengan tingkat pendidikan tinggi memiliki pekerjaan dengan tanggung jawab yang lebih besar dan memiliki tingkat stress tinggi, atau mungkin individu yang dengan tingkat pendidikan tinggi memiliki ekspektasi yang terlalu tinggi terhadap pekerjaan mereka dan membuat individu tersebut menjadi distress jika ekspektasi itu tidak terealisasi. Sehingga, tingkat pendidikan tinggi maupun rendah tidak akan mempengaruhi terjadinya burnout.

Menurut asumsi peneliti, individu yang belum menikah, menikah dan bercerai bisa saja mengalami burnout. Meskipun individu yang telah menikah memiliki pasangan, apabila dukungan sosial tidak didapatkan akan sulit menghindari burnout. Menurut Dam \& Marcus (2007) tersedianya sumber dukungan, sehingga individu memiliki rasa percaya diri karena yakin ada orang lain yang dapat membantunya saat mengalami kesulitan.

Bentuk dukungan sosial bukan hanya dari orang terdekat saja, tetapi dari teman sekerja, ataupun tim kesehatan lainnya, bentuk dukungan yang suportif memungkinkan individu untuk menghindari burnout yang terjadi. Menurut Fakhar et al (2012) burnout sangat rentan terjadi pada perawat karena 
sifat dari profesi mereka, sehingga dukunan sosial di tempat kerja dapat mengurangi terjadunya burnout. Sehingga, perawat yang menikah ataupun yang belum menikah tidak akan mempengaruhi terjadinya burnout.

Menurut asumsi peneliti, individu sudah lama bekerja juga memiliki kecendrungan terhadap burnout, begitu juga individu yang baru bekerja juga dapat mengalami burnout. Burnout dapat saja terjadi karena mereka bekerja dengan orang-orang yang tidak berkompeten. Menurut Olayinka et al (2013) perawat yang tidak berkompeten sangat rentan terhadap kesalahan dalam pengambilan keputusan klinis mereka. Sehingga, apabila bekerja dengan mereka yang tidak berkompeten akan memiliki kecendrungan terhadap burnout.

Lingkungan kerja yang bervariasi dalam tiap pekerjaan juga dapat memepengaruhi meskipun perawat baru saja bekerja ataupun yang sudah lama bekerja, ketika pengalaman individu yang dirasakan berdampak negatif, tidak dapat dihindari dan burnout cenderung dapat dialami individu kapan saja. Menurut Sydney et al (2015) efek dari berbagai faktor berbahaya dari lingkungan kerja menyebabkan burnout pada perawat. Sehingga, perawat dengan lama bekerja baru maupun lama tidak akan ada pengaruh pada burnout.

\section{SIMPULAN}

Hasil penelitian yang telah dilakukan dilakukan di RSJ Soeharto Heerdjan Jakarta diambil kesimpulan sekaligus menjawab tujuan peneliti yaitu burnout yang dirasakan perawat kesehatan jiwaberada pada level tinggi dan untuk semua domain burnout yaitu kelelahan emosional, depersonalisasi, pencapaian prestasi pribadi.

\section{UCAPAN TERIMA KASIH}

Ucapan terima kasih yang sebesarbesarnyakepada Direktur RSJ
Soehato Heerdjan Jakarta, sebagi tempat penelitian. Terimakasih juga kepada semua pihak terkait yang telah membantu dan mendukung peneliti dalam proses pelaksanaan penelitian sehingga tulisan ilmiah ini dapat diselesaikan.

\section{DAFTAR PUSTAKA}

Alfiyah. (2013). Faktor-faktor yang berhubungan dengan turnover intention perawar di brawijaya woman and children Jakarta. Skripsi. Universitas Islam Negeri Syarif Hidayatullah Fakultas Kedokteran dan Ilmu Kesehatan.

AlSuliman, et al. (2014). Burnout among nurses in tabuk military hospital International. Journal of Medical Science and Public Health. 3(5).

American Health Care Association. (2011). Report findings nursing facility staffing survey 2010 .

Bloom, S.L \& Farragher, B. (2011). Destroying Sanctuary: The Crisis in Human Service Delivery Systems. New York: Oxford University Press, Inc.

Chakraborty, et al. (2012). Internal predictors of burnout in psychiatric nurses: An Indian study. Industrial Psychiatry Journal. 21(2).

Dam, N.V \& Marcus, J. (2007). Organization And Management And International Approach. Netherlands: Noordhoff Uitgevers bv gronigen.

Damanik,D.N. (2015). Hubungan Rotasi kerja dan burnout dengan kepuasan kerja perawat di rumah sakit jiwa Prof. Dr. Muhammad Ildrem Medan. Tesis. Universitas Sumatera Utara Fakultas Keperawatan.

Fakhar, M.F, et al. (2012). Relationship between supervisor social support and burnout in nurses. Iran Journal of Nursing. 25(79): 6371. 
Fazelzadeh et al. (2008) Burnout in hospital nurses: a comparison of internal, surgery, psychiatry and burns wards. International Nursing Review. 55 (62-67).

Fradelos, E, Mpelegrinos, S. Mparo, Ch, Vassilopoulou Ch , Argyrou, P, Tsironi, M, Zyga, S, Theofilou, P. (2014). Burnout syndrome impacts on quality of life in nursing professionals: The contribution of perceived social support. Prog Health Sci, 4(1): 109-102.

Geri \& Flynn. (2008). Nursing Policy Research Turning EvidenceBased Research Into Health Policy. New York. Springer Publishing Company.

Hamaideh, S. (2011). Burnout, social support, and job satisfaction among jordanian mental health nurses. Issues in Mental Health Nursing, 32:234-242.

Harkin, M \& Melby, V. (2014). Comparing burnout in emergency nurses and medical nurses. Clinical Nursing Studies, 2(3): 152-63

Holland, J.C, Breitbart, W.S, Butow, P.S, Jacobsen, PB, Loscalzo,M.J, Mccorkle, R. (2015). PsychoOncology Third Edition. United States America: Oxford University Press.

Jaworek \& Dyląg. (2015). Work-related factors and age as determinants of three burnout dimensions among Polish hospital nurses. Jagiellonian Journal of Management. 1(1): 33-49.

Khodadadizadeh, et al. (2012). Occupational burnout assessment among nurses working in Iranian hospital. JOHE, Summer. 1 (2).

Khamisa,N, Oldenburg,B, Peltzer, K and Ilic, D. (2015). Work Related Stress, Burnout, Job Satisfaction and General Health of Nurses. International Journal of
Environmental Research and Public Health: 12, 652-666.

Kusano, et al. (2013). Burnout in united states academic chairs of radiation oncology programs. International Journal Oncology Biology Physical. 88(2): 363-8.

Leiter, Bakker \& Maslach. (2014). Burnout At Work: A Psychological Perspective. London and New York: Psychology Press Taylor \& Francis Group, LLC.

Lerkiatbundit \& Borry. (2009). Moral Distress Part I: Critical Literature Review on Definition, Magnitude, Antecedents and Consequences. Thai Journal of Pharmacy Practice, 1(1): 1-11.

Lee \& Ashforth. (1996). A meta analytic examination of the correlates the three dimensions of job burnout. Journal Of Applied Psychology. 81(2)123-133.

Lori L.A. (2015). Burnout: Impact on Nursing and Quality of Care. www.NetCE.com

Lu, J. (2008). Organizational role stress indices affecting burnout among nurses. Journal of international women's studies. 9(3), 63-78.

Maslach, C. \& Jackson, S.E. (1981). The measurement of experienced burnout. Journal of occupational behaviour, 2: 99-113.

Mohamed. (2016) Burnout \& Job Satisfaction Among Nurses' in Baghdad Psychiatric Hospitals. PLoS ONE. 10(6).

Ndetei, D. M et al (2008). Burnout in staff working at the Mathari psychiatric hospital. African Journal of Psychiatry: (11), 199203.

Nie, et al (2015). Correlation of burnout with social support in hospital nurses. International Journal Clinical Exp Med. 19144-9.

Olayinka, O, et al. (2013). Occupational stress management among nurses 
in selected hospital in Benin city, Edo State, Nigeria. European Journal of Experimentgal Biology. 3(1): 473-481.

Poghosyan, et al . (2010). Nurse Burnout and Quality of Care: CrossNational Investigationin Six Countries. Journal Res Nurs Health. 33(4): 288-298.

$\mathrm{Qu} \&$ Wang. (2015). Study on the relationships between nurses' job burnout and subjective wellbeing. Journal Chinese Nursing Research.12(1): 249-259.

Rashedi, et al. (2014). Burnout and sociodemographic characteristics of nurses in iran. GMJ. 3(4): 223-7

Ribeiro, V.F et al (2014). Prevalence of burnout syndrome in clinical nurse at hospital excellence. International Archives and Medicine, 7:22.

Teater \& Ludgate. (2014). Overcoming Compassion Fatigue: a practical resilience workbook. USA: PESI Publishing \& Media.

Thomas, S.P. (2014). Transforming Nurse's Stress and Anger Step
Toward Healing Second Edition. USA: Springer Publishing Company.

Warner, H.R. (2014). Stress, Burnout, and Addiction in the Nursing Profession. United States America: Xlibris LLC.

Yazici, A.B et al. (2014). The relationship between temperament and character traits and burnout among nurses. Journal psycho psychoter. 4:154

Yousef \& Ghassemi. (2006). Job burnout in psychiatric and medical nurses in Isfahan, Islamic Republic of Iran. La Revue de Santé de la Méditerranée orientale Journal. $12(5)$.

Ziaei,H, Yarmohammadi, Moradi, M, Khandan, M. (2015). Level of Workload and Its Relationship with Job Burnout among Administrative Staff. International Journal Of Occupational Hygiene. 7(1): 5360. 